\title{
Mexican Chihuahua Cheese: Sensory Profiles of Young Cheese ${ }^{1}$
}

\author{
D. L. Van Hekken, ${ }^{\star 2}$ M. A. Drake,† F. J. Molina Corral,‡ V. M. Guerrero Prieto,ł and A. A. Gardea‡ \\ *Dairy Processing and Products Research Unit, USDA, ARS, Eastern Regional Research Center, \\ 600 East Mermaid Lane, Wyndmoor, PA 19038 \\ †Department of Food Science, Southeast Dairy Foods Research Center, North Carolina State University, Raleigh \\ ¥Centro de Investigación en Alimentación y Desarrollo (CIAD), Cuauhtémoc, Chihuahua, México
}

\section{ABSTRACT}

Sensory profiles of fresh semihard Chihuahua cheese produced in the northern Mexican state of Chihuahua were developed to characterize the flavors and textures of this traditionally made Hispanic-style cheese. Multiple allotments of Chihuahua cheese, 9 brands made with raw milk (RM) and 5 brands made with pasteurized milk (PM), were obtained within $3 \mathrm{~d}$ of manufacture from 12 different cheese plants throughout Chihuahua, México. Cheeses were shipped overnight to Wyndmoor, Pennsylvania, and flavor analyses were conducted within 14 to $18 \mathrm{~d}$ after manufacture. Four brands (2 RM and 2 PM cheeses) were then selected and multiple allotments were shipped at 3 distinct seasons over a 1-yr period for evaluation of flavor and texture. Microbial analysis was conducted prior to testing to ensure product safety. Descriptive analyses of cheese flavors and textures were conducted with panelists trained to use a universal or product-specific Spectrum intensity scale, respectively. Sensory profiles of cheeses varied among the different manufacturers. The most prominent flavor attributes were salty, sour, diacetyl, cooked, whey, bitter, and milkfat. The RM cheeses had more intense sour, bitter, and prickle scores than the PM cheeses. Many cheese texture attributes were similar, but RM cheeses were perceived as softer than PM cheeses. As the demand for Hispanicstyle cheeses increases, defining and understanding the sensory attributes of traditionally made Mexican cheeses provides guidance to cheese manufacturers as new ways are explored to improve the production and shelf life of the cheeses.

Key words: Hispanic-style cheese, flavor, texture, raw milk

Received December 12, 2005.

Accepted March 28, 2006.

${ }^{1}$ Mention of trade names or commercial products in this article is solely for the purpose of providing specific information and does not imply recommendation or endorsement by the U.S. Department of Agriculture.

${ }^{2}$ Corresponding author: dvanhekken@errc.ars.usda.gov

\section{INTRODUCTION}

In the United States, the growth in the Hispanic population and the popularity of Hispanic-style cuisine has driven the growth in the manufacture of Hispanic-style cheeses, reaching 142 million pounds in 2004 (National Agricultural Statistics Service, 2005). Hispanic-style cheeses are cheeses developed in México, Latin America, and the Caribbean and are usually based on European cheese-making traditions and modified to accommodate local cheese-making conditions and consumer preferences (Van Hekken and Farkye, 2003). The quality traits that define the different Hispanic-style cheeses have not been studied extensively and need to be established to ensure that the unique attributes of the traditionally made cheeses are maintained.

In the northern Mexican state of Chihuahua, the Mennonite communities manufacture a semihard cheese called queso Chihuahua or queso Chester, which is usually consumed within 1 mo after manufacture. The Chihuahua cheese is made with either raw milk (RM) or pasteurized milk (PM) and "displays mild to tangy flavor.... The color is dull white and body medium hard with crumbly texture" (Kosikowski and Mistry, 1997a). Further investigation into the sensory qualities of this cheese has not been conducted.

Sensory attributes (flavor and texture) are critical to the identity of cheese and consumer acceptance. Although many approaches have been developed to evaluate the sensory attributes of foods, sensory evaluation of cheese using descriptive analysis as a research tool has blossomed in the last decade (Drake and Civille, 2003; Drake, 2004). Descriptive analysis is an integral part of identifying differences in ingredients (Drake et al., 1996; Tungjaroenchai et al., 2001; Shakeel-Ur-Rehman et al., 2003), characterizing the aromas and flavors in cheeses (Suriyaphan et al., 2001; Drake et al., 2003; Avsar et al., 2004), and evaluating the texture or body of cheese (Drake et al., 1999a) in comparison with instrumentally measured rheology (Drake et al., 1999b, 1999c; Brown et al., 2003). Descriptive analysis requires specific uniform terminology and evaluation techniques (Drake and Civille, 2003) and has led to the development of a specific language of attributes to describe the flavor of 
Cheddar cheese (Drake et al., 2001) and the texture of cheeses in general (Drake et al., 1999a).

Scientists from the Dairy Processing and Products Research Unit, in collaboration with those from the Centro de Investigación en Alimentiación y Desarrollo (CIAD), determined the quality traits of commercial Chihuahua cheeses manufactured in the state of Chihuahua, México. The project involved characterizing a variety of aspects of the RM and PM cheeses, including the manufacturing procedures and the chemical (Tunick et al., accepted; Van Hekken et al., accepted), microbiological (Bricker et al., 2005; Tunick et al., accepted), and rheological properties (Van Hekken et al., accepted) of Chihuahua cheeses. In this portion of the study, scientists at the Dairy Processing and Products Research Unit and CIAD, in collaboration with researchers at North Carolina State University, characterized the sensory flavors and textures of fresh RM and PM Chihuahua cheeses.

\section{MATERIALS AND METHODS}

\section{Commercial Cheeses}

A general description of the Chihuahua cheese-making protocol follows, although a number of plants used conditions outside of those described and not all manufacturers provided details (Tunick et al., accepted). Cheese milk was warmed to 30 to $37^{\circ} \mathrm{C}$ and $\mathrm{CaCl}_{2}$ was added. Starter cultures were added only to milk that had been pasteurized. Commercial rennet was added to coagulate the milk and the curd was cut into $6-\mathrm{mm}$ cubes 30 to 40 min later. Curds were cooked at 37 to $39^{\circ} \mathrm{C}$ for 5 to 90 min for RM cheeses and at 45 to 90 min for the PM cheeses. Whey was drained completely and the curd was cheddared for 20 to 40 min to promote whey removal. Curds were milled (13 to $51 \mathrm{~mm}$ in size), salted (1 to 4 $\mathrm{g}$ of salt $/ \mathrm{kg}$ of curd), and pressed (120 to $280 \mathrm{~Pa}$ ). Blocks (1-kg) of cheese were packaged in plastic shrink-wrap and refrigerated.

Multiple blocks of semihard Chihuahua cheeses made with either RM or PM were obtained within $3 \mathrm{~d}$ of manufacture from different commercial cheese plants throughout the state of Chihuahua, México. Each cheese block obtained from the cheese plant was then placed inside a resealable plastic pouch, packed among cold packs in large coolers, and shipped overnight to the Dairy Processing and Products Research Unit, Wyndmoor, Pennsylvania. A sufficient number of cold packs were used to ensure that the cheese remained adequately cold throughout transportation. Once received, the cheese blocks were stored at $4^{\circ} \mathrm{C}$. Three blocks from each manufacture were opened aseptically and portions were sent immediately for microbiological testing. A certified laboratory conducted microbiological screenings (Listeria monocytogenes, Escherichia coli O157:H7, Staphylococcus aureus enterotoxin, and Campylobacter spp.) for all samples prior to use in the sensory study to ensure the safety of the cheeses. Another portion was removed from each block of cheese, repackaged, and stored at $4^{\circ} \mathrm{C}$ for compositional analysis to begin $10 \mathrm{~d}$ after manufacture.

Moisture was measured in triplicate using the forceddraft oven method (method 948.12; AOAC, 1997). Fat content was determined in duplicate using the modified Babcock method (Kosikowski and Mistry, 1997b). Nitrogen content of the cheeses was measured in duplicate using an FP-2000 nitrogen analyzer (Leco Corp., St. Joseph, MI) and total protein content was calculated by multiplying the percentage of nitrogen by 6.38 . Levels of $\mathrm{NaCl}$ were determined in duplicate using high-range chloride titrators (Hach Co., Loveland, CO). Cheeses were tested using the Charm Pas Lite test (Charm Sciences, Inc., Lawrence, MA) for inactivation of alkaline phosphatase. Cheeses in the PM category showed no phosphatase activity, including brand $\mathrm{Q}$, which was made from milk heated to $73^{\circ} \mathrm{C}$ for $3 \mathrm{~s}$.

The research project was conducted in 2 phases. Phase 1 entailed the initial evaluation of 14 different brands of semihard Chihuahua cheeses that were obtained from 12 different commercial cheese manufacturers throughout the state of Chihuahua, México. During 2001, multiple shipments (4 different brands per shipment) of fresh cheeses were evaluated to identify descriptors for the cheeses and to train the descriptive analysis panel. In June 2004, all 14 brands were obtained at one time for a final flavor analysis. Nine brands of cheese were made from RM (no starter culture added; designated brands A to $\mathrm{H}$, and $\mathrm{J}$ ) and 5 brands of cheese were made from PM (commercial starter culture added; designated brands L to $\mathrm{N}, \mathrm{P}$, and $\mathrm{Q}$ ). A minimum of 3 blocks of each brand of cheese remained in storage at $4^{\circ} \mathrm{C}$ until sensory evaluations were conducted at 14 to $18 \mathrm{~d}$ after manufacture.

In phase 2, conducted in 2002 and 2003, multiple blocks of 4 selected brands (2 RM and 2 PM cheeses) were obtained during the 3 distinct northern México seasons (winter, collected in December to January; spring, collected in May; and fall, collected in September) and shipped as described above to Wyndmoor, Pennsylvania. Upon receipt, at least 2 blocks of each brand were then repacked in fresh cold packs and shipped overnight to North Carolina State University for texture evaluation. Samples for sensory evaluation were stored at $4^{\circ} \mathrm{C}$ until tested at 14 to $18 \mathrm{~d}$ after manufacture. The 4 brands were selected from among the 14 brands characterized in phase 1 based on similar composition and rheological properties. Because of clustering of a number of the RM cheeses, an informal ranking of coded RM cheeses was conducted by approximately 30 Mexican Chihuahua cheese manufacturers to identify the cheeses with the 
Table 1. Lexicon for the flavors detected in Chihuahua cheeses, and descriptors incorporated from the Cheddar cheese lexicon (Drake et al., 2001)

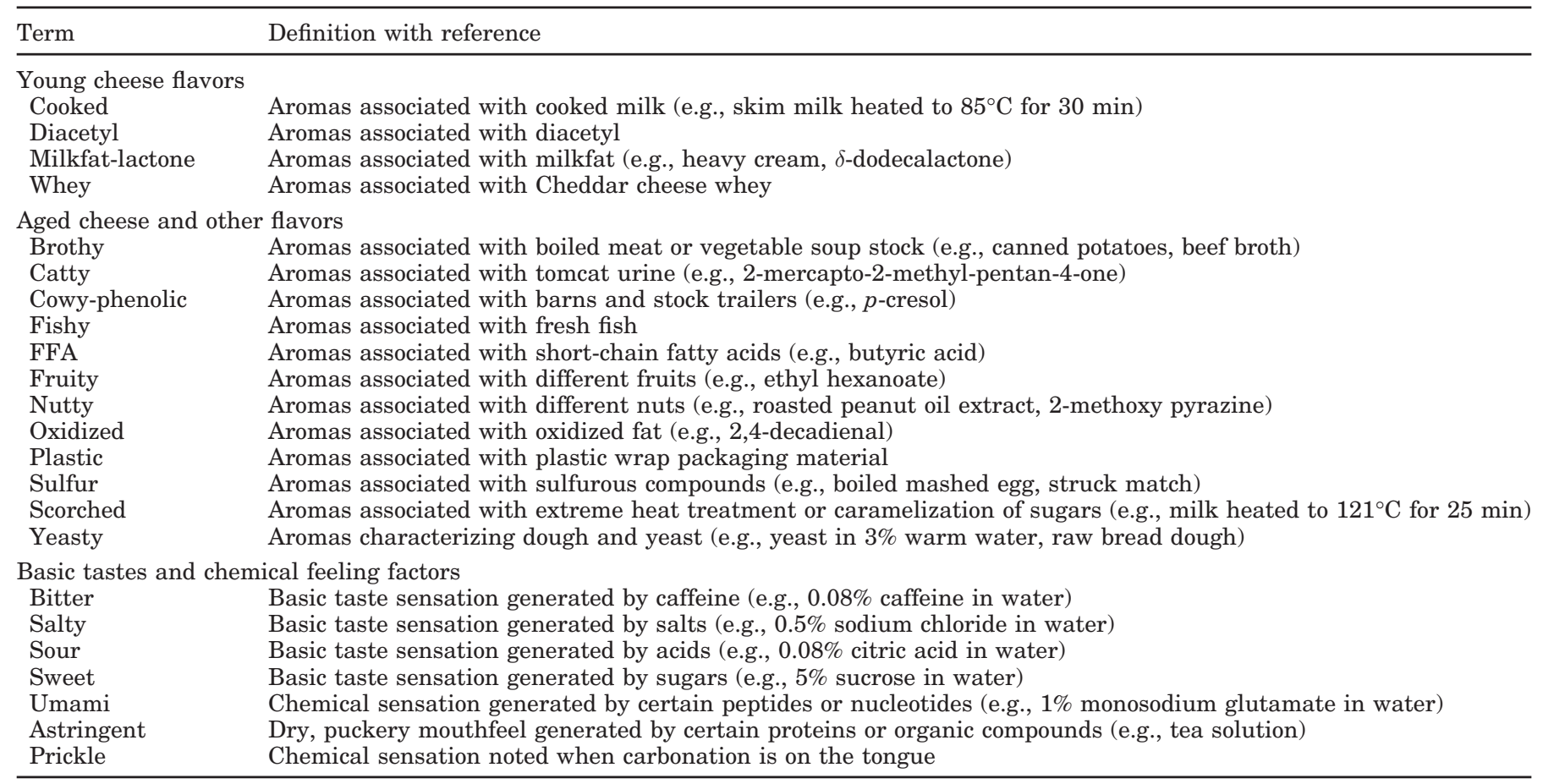

flavor closest to the ideal flavor for this style of cheese; the top 2 were used in the phase 2 study.

\section{Flavor Attributes}

Two researchers well trained in cheese sensory evaluation (over $500 \mathrm{~h}$ each) sampled a variety of Americanand Mexican-manufactured Hispanic-style cheeses (including multiple 2001 shipments of Chihuahua cheeses) and selected aroma and flavor descriptors to be used to evaluate Hispanic-style cheeses (Table 1). The majority of the descriptors were selected from the Cheddar cheese lexicon (Drake et al., 2001). Descriptors such as astringent, fishy, and plastic were added because they were occasionally detected in samples. Flavor panelists were selected based on their ability to detect differences in regular and low-salt cheeses and were trained to use the descriptors on a wide variety of European, American, and Hispanic-style cheeses.

Flavor evaluation of cheese was conducted by 8 experienced descriptive analysis panelists ( 2 female, 6 male) who were trained (minimum of $40 \mathrm{~h}$ ) to use a universal Spectrum 15-point intensity scale (Meilgaard et al., 1999) using selected terminology (Table 1). Evaluations were conducted in a sensory laboratory with isolated, environmentally controlled booths and normal lighting. Bottled water, unsalted crackers, and references for basic tastes and young cheese flavors were available to panelists at all times. Cubed samples (from the interior of the cheese blocks) were placed in 3-digit-coded 59-mL (2-oz) soufflé cups and capped. Samples were brought to room temperature $\left(21^{\circ} \mathrm{C}\right)$ before evaluation. Each brand was evaluated in duplicate by each panelist using a randomized balanced block design. For phase 1, all 14 brands were evaluated within a 5 -d period. For each shipment in phase 2 , the 4 brands of cheese were evaluated over a 2 -d period. Between 4 and 8 samples were evaluated at any one time.

\section{Texture Attributes}

A texture evaluation of the cheese was conducted by 15 descriptive analysis panelists trained (at least $20 \mathrm{~h}$ each with cheese texture) to use a 15-point productspecific intensity scale (Drake et al., 1999a) as described and modified by Brown et al. (2003) using the Spectrum method (Table 2). Evaluations were conducted in a sensory laboratory with isolated booths and using normal lighting. Appropriate references and a warm-up sample were available in each session. Samples were cut from the interior of the cheese blocks into $1.27 \mathrm{~cm}^{3}$ cubes, placed in capped 59-mL (2-oz) soufflé cups, and tempered to $15^{\circ} \mathrm{C}$ in an incubator before evaluation. Panelists received 4 cubes at a time from the same brand of cheese. The 4 brands of cheese were evaluated in triplicate by 


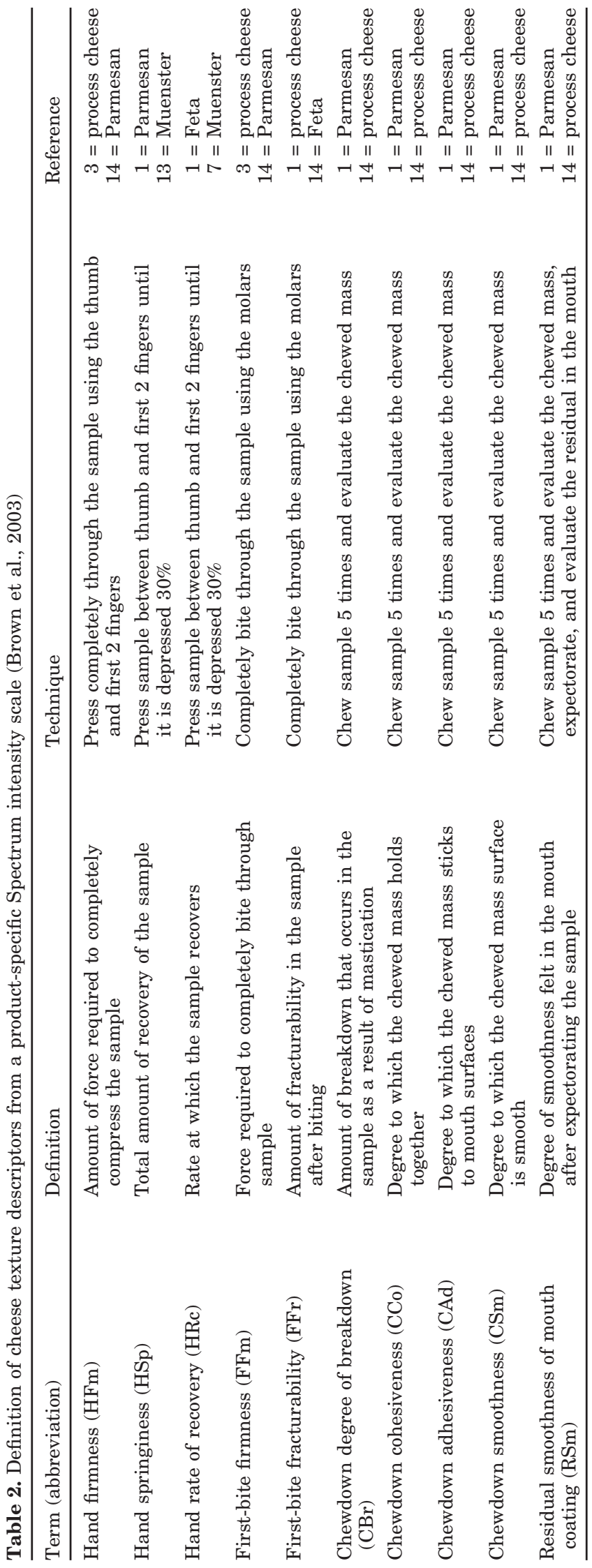

Table 3. Composition (moisture, fat, and protein) of 14 different brands of commercial Chihuahua cheeses and overall means for raw milk (RM) or pasteurized milk (PM) cheeses

\begin{tabular}{llll}
\hline Cheese brand & Moisture & Fat & Protein \\
\cline { 2 - 4 } & & & \\
RM & & & \\
A & $38.3^{\text {ghi }}$ & $33.8^{\text {abc }}$ & $25.8^{\text {fgh }}$ \\
B & $40.0^{\text {cdefg }}$ & $31.7^{\text {bcd }}$ & $24.9^{\mathrm{h}}$ \\
C & $41.9^{\text {bcd }}$ & $32.3^{\text {bcd }}$ & $25.9^{\text {efgh }}$ \\
D & $37.7^{\text {hi }}$ & $33.0^{\text {bcd }}$ & $29.1^{\mathrm{a}}$ \\
E & $38.8^{\text {fghi }}$ & $32.4^{\text {bcd }}$ & $27.3^{\text {bcd }}$ \\
F & $38.2^{\text {ghi }}$ & $36.4^{\mathrm{a}}$ & $27.7^{\text {bc }}$ \\
G & $39.9^{\text {defg }}$ & $33.3^{\text {abc }}$ & $27.4^{\text {bcd }}$ \\
H & $41.4^{\text {bcde }}$ & $30.7^{\text {cd }}$ & $26.7^{\text {cdef }}$ \\
J & $38.9^{\text {fgh }}$ & $33.1^{\text {bcd }}$ & $27.1^{\text {bcde }}$ \\
RM mean & $39.2^{\mathrm{B}}$ & $33.0^{\mathrm{A}}$ & $26.7^{\mathrm{A}}$ \\
PM & & & \\
L & $39.1^{\text {efgh }}$ & $35.3^{\text {ab }}$ & $28.6^{\text {ab }}$ \\
M & $42.8^{\mathrm{b}}$ & $32.0^{\text {bcd }}$ & $26.6^{\text {cdefg }}$ \\
N & $42.0^{\text {bc }}$ & $31.4^{\text {cd }}$ & $26.2^{\text {defg }}$ \\
P & $45.7^{\mathrm{a}}$ & $31.4^{\text {cd }}$ & $24.8^{\mathrm{h}}$ \\
Q & $40.8^{\text {bcdef }}$ & $30.1^{\text {d }}$ & $27.0^{\text {cdef }}$ \\
PM mean & $42.3^{\mathrm{A}}$ & $31.8^{\mathrm{B}}$ & $26.5^{\mathrm{A}}$ \\
\hline
\end{tabular}

${ }^{\mathrm{a}-\mathrm{i}}$ Means for individual brands within a column that do not share the same lowercase letter are different $(P<0.05)$.

${ }^{\mathrm{A}, \mathrm{B}}$ Overall means for RM or PM cheeses within a column that do not share the same uppercase letter are different $(P<0.05)$.

each panelist in a randomized balanced block design over a 2 -d period.

\section{Statistics}

Composition and sensory data were analyzed using statistical software (SAS Version 8.2; SAS Institute, 2001). A GLM with least squared means separation was calculated to compare brand means; differences were considered significant at $P<0.05$. Principal component (PC) analysis was used to determine the overall variability among the brands and relationships among the variables. Data from phase 2 were analyzed using season as a dependent variable.

\section{RESULTS AND DISCUSSION}

\section{Phase 1}

Chihuahua cheeses showed variations in composition among the different brands (Table 3 ). The majority of the Chihuahua cheeses ranged from 38.2 to $42.8 \%$ moisture, although brand D contained $37.7 \%$ moisture and brand $\mathrm{P}$ contained $45.7 \%$ moisture. Fat levels ranged from 30.1 to $36.4 \%$, and protein levels ranged from 24.8 to $29.1 \%$. All cheeses contained from 1.0 to $1.5 \%$ salt (wet weight). The 9 brands of RM Chihuahua cheese averaged $39.2 \pm$ $1.4 \%$ moisture, $33.0 \pm 1.2 \%$ fat, and $26.6 \pm 1.3 \%$ protein, whereas the 5 brands of PM cheese contained $42.3 \pm$ $1.4 \%$ moisture, $31.8 \pm 0.8 \%$ fat, and $26.5 \pm 1.2 \%$ protein. 
Table 4. Intensity scores for the flavors identified in 14 brands of Chihuahua cheese made with raw milk (RM) or pasteurized milk (PM) ${ }^{1}$

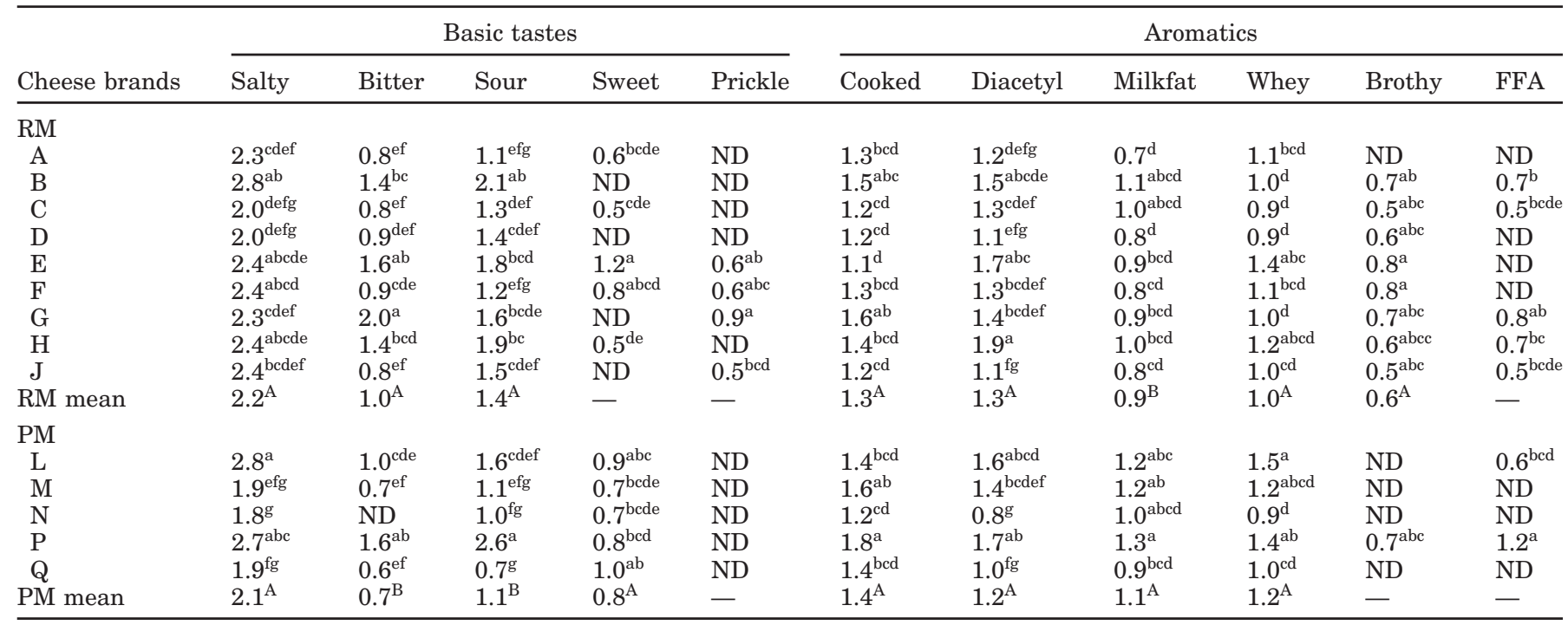

${ }^{\mathrm{a}-\mathrm{g}}$ Means for individual brands within a column that do not share the same lowercase letter are different $(P<0.05)$.

${ }^{\mathrm{A}, \mathrm{B}}$ Overall means for RM or PM cheeses within a column that do not share the same uppercase letter are different $(P<0.05)$.

${ }^{1} \mathrm{ND}=$ Not detected.

Overall, the PM cheeses contained higher levels of moisture and lower levels of fat $(P<0.05)$ than did the RM cheeses. The chemical composition of all brands conformed to the Mexican Official Standards for Chihuahua Cheese (Dirección General de Normas, 1994).

Chihuahua cheeses were mildly flavored, with the primary flavors (salty, sour, diacetyl, cooked, whey, bitter, milkfat) found in all brands at intensity scores from 1.0 to 3.0 (Table 4). Other minor flavors (intensity scores from 0.5 to 0.9 ) included sweet, brothy, and FFA. The cheeses were all very young at the time of sensory analysis, which is typically when they are consumed. Young cheese flavors such as cooked, whey, and diacetyl would be expected to predominate (Drake et al., 2001). The strongest flavor note in Chihuahua cheese was salty (ranging in intensity from 1.8 to 2.8 ) and reflected the 1.0 to $1.5 \%$ salt measured in the cheeses. Not all chemical concentrations were related to flavor scores because the cheeses contained 30 to $36 \%$ fat and the milkfat-lactone flavor was detected at low intensities (ranging from 0.7 to 1.3). Detection of flavors is influenced by many factors, including release of flavor compounds from the cheese, detection of threshold concentrations by the panelist, and the presence of other flavors and tastes (Drake, 2004).

Flavor profiles of the different brands of RM and PM cheeses (Table 4) illustrated that the brands were similar, but not identical, in flavor. The intensity scores for different flavors varied among the brands as much as 1.0 to 1.9 for salty, bitter, sour, diacetyl, and FFA, whereas less variation (0.5 to 0.9 ) was observed for cooked and whey. A sweet taste was detected in all of the PM cheeses but in only 5 of the RM cheeses, whereas brothy was detected in 8 of the RM cheeses and only 1 of the PM cheeses. Free fatty acid was detected in 5 of the RM cheeses and 2 of the PM cheeses. Four of the RM cheeses had a prickle mouthfeel that was absent from the PM cheeses. Comparison of the overall means showed that the RM cheeses were more bitter and sour, and were lower in the sweet and milkfat scores than the PM cheeses. The RM cheeses tended to have higher sour scores and lower $\mathrm{pH}$ (data not shown) than the PM cheeses. The PM cheese with a sour score of 2.6 also had a pH below 5.0. A few flavors were noted at low intensities in only a few of the brands; for example, "cowy" was detected in brand $\mathrm{H}$, "fruity" in brands $\mathrm{H}, \mathrm{L}$, and $\mathrm{P}$, and "oxidized" in brands M and P.

Chihuahua cheese has been described as "mild to tangy" in flavor (Kosikowski and Mistry, 1997a). The flavor profiles generated by the descriptive analysis panel showed the cheese to be mild and that the variation among brands appeared in the intensities of the bitter, sour, and prickle flavor notes. In an informal flavor ranking of coded RM Chihuahua cheese by 30 Chihuahua cheese manufacturers, brand $G$ was selected as being closest to having the "ideal" Chihuahua flavor (data not presented). Brand $\mathrm{G}$ had the highest bitter and prickle scores of all of the brands, slight brothy (0.7) and FFA (0.8) flavors, and very slight intensities (0.4) of cowy, oxidized, and yeasty flavor notes. This complex flavor profile helps to define the "tangy" flavor mentioned by Kosikowski and Mistry (1997a). 
The lexicon for Cheddar cheese was developed using cheeses from 2 mo to $3 \mathrm{yr}$ in age (Drake et al., 2001), and the terminology fit very well in describing the young Chihuahua cheese. The presence of basic tastes and young cheese flavors are typical in fresh, undeveloped cheeses. The RM cheeses tended to have higher bitter, sour, and prickle scores than did the PM cheeses. This could be attributed to more extensive hydrolysis action occurring in RM cheeses with a more diverse bacterial population (Bricker et al., 2005). Four of the 5 PM cheeses had sour taste scores from 0.7 to 1.6 , whereas brand $\mathrm{P}$ had a score of 2.6. The mouthfeel factor "prickle" that was detected in the RM Chihuahua cheeses is infrequently used when describing Cheddar cheese, as is the descriptor "oxidized." Flavor intensity scores reported by Drake et al. (1999a) for Cheddar cheeses at 1 and 2 mo of age were similar for diacetyl and salty; higher for whey, milkfat, sweet, and sour; and lower for bitter and FFA scores than those reported for Chihuahua cheeses. These differences may be due to the differences in cheese style, age, and microflora of the Cheddar and Chihuahua cheeses.

The aerobic microflora in the Mexican cheeses ranged from 8.5 to $9.6 \log _{10} \mathrm{cfu} / \mathrm{g}$ in the RM samples and from 6.1 to $8.7 \log _{10} \mathrm{cfu} / \mathrm{g}$ in the PM samples (Tunick et al., accepted). This is above the recommended level of 5.7 $\log _{10} \mathrm{cfu} / \mathrm{g}$ cited in Mexican cheese standards (Dirección General de Normas, 1994). Bricker et al. (2005) reported that the RM and PM Chihuahua cheeses contained similar levels of mesophilic bacteria and that the thermophilic bacteria were 1 to $1.5 \log _{10} \mathrm{cfu} / \mathrm{g}$ lower in the PM cheeses. The presence of the lactic acid bacteria were expected in the cheeses; these contribute to flavor development. The RM cheeses contained low levels of enterococci, coliforms, and coagulase-positive staphylococci that were not present in the PM cheeses. These organisms will bring enzymes into the cheese system that can influence the flavor development, such as the bitter and prickle attributes. At d 18 after manufacture, the differences in flavor were slight. In Mexico, Chihuahua cheese typically is consumed within 1 to $6 \mathrm{wk}$ after manufacture and does not allow for extensive flavor development. In areas where consumers prefer longer aging of their cheeses, the extent of the bitter and prickle flavors that develop in Chihuahua cheese as it ages must be addressed to determine acceptability of the cheese.

Principal component analysis, a multivariate statistical approach used to examine relationships between observations, illustrated the variability in flavors among the different brands of RM and PM Chihuahua cheeses (Figure 1). The first PC accounted for $36.4 \%$ of the variation among the different brands of cheese, and the second PC accounted for $17.7 \%$; the first $4 \mathrm{PC}$ accounted for $76 \%$ of the variation. All brands were fairly well clustered to the center of the biplot, ranging from 1.6 to -1.1 on PC1 and from 1.5 to -0.9 on PC2. All of the PM cheeses had positive PC2 values. All of the RM cheeses (except for brand $\mathrm{C}$ ) had negative $\mathrm{PC} 2$ values, with brands $\mathrm{B}, \mathrm{E}, \mathrm{G}$, and $\mathrm{H}$ having positive $\mathrm{PC} 1$ values and brands $\mathrm{A}, \mathrm{C}, \mathrm{D}$, $\mathrm{F}$, and $\mathrm{J}$ having negative $\mathrm{PC} 1$ values. The descriptor vectors of interest for Chihuahua cheese had positive PC1 correlations, except for sweet. This is different from what was reported for Cheddar cheese. Drake et al. (2001) found that as cheese aged, the young flavors decreased as the aged flavors appeared, giving a negative correlation. In other aspects, the relationship among the vectors agreed with that for Cheddar (e.g., young flavor vectors were clustered together; bitter, salty, and sour were clustered together and were opposite of sweet). The highest correlations among the flavor descriptors for the Chihuahua cheese were between the basic tastes and aged flavors; sour and FFA (0.883); and bitter and prickle (0.817). Other high correlations were among basic tastes (bitter and sour, 0.756; sour and salty, 0.741), basic tastes and young flavors (sour and diacetyl, 0.750; bitter and diacetyl, 0.713), young flavors (cooked and milkfat, 0.736 ), and aged flavors (brothy and prickle, 0.720). Principal component analysis illustrated the diversity in the flavors found among the different brands of Chihuahua cheese.

\section{Phase 2}

Concern over possible cheese milk seasonal effects on the sensory properties of the Chihuahua cheese prompted the second phase of the study. Chihuahua has 3 distinct seasons, which can influence the diet of the pasture-fed cows and does influence the microflora present in the RM cheeses and the rheology of RM and PM cheeses (our unpublished data, 2006). The diverse microflora identified in Chihuahua cheese (Bricker et al., 2005) may also be altered with the changing of the seasons.

The composition of the 4 brands of Chihuahua cheese selected as representative of this style altered with the change in seasons (data not shown). Fat contents were most variable, being the lowest in the winter (22.5 to $25.0 \%)$ and increasing significantly $(P<0.05)$ as the seasons progressed: Spring ranged from 30.8 to $31.6 \%$ fat, and late summer ranged from 33.5 to $35.5 \%$ fat. Cheese protein levels ranged from 24.1 to $26.2 \%$ in the spring and late summer, and were significantly $(P<0.05)$ higher in the winter (29.8 to $31.1 \%$ ). Cheese made in the winter had the highest moisture levels, although this difference was significant $(P<0.05)$ in only 2 of the brands. As seen in phase 1, the PM cheeses were higher in moisture, similar in protein, and lower in fat than the RM cheeses. 


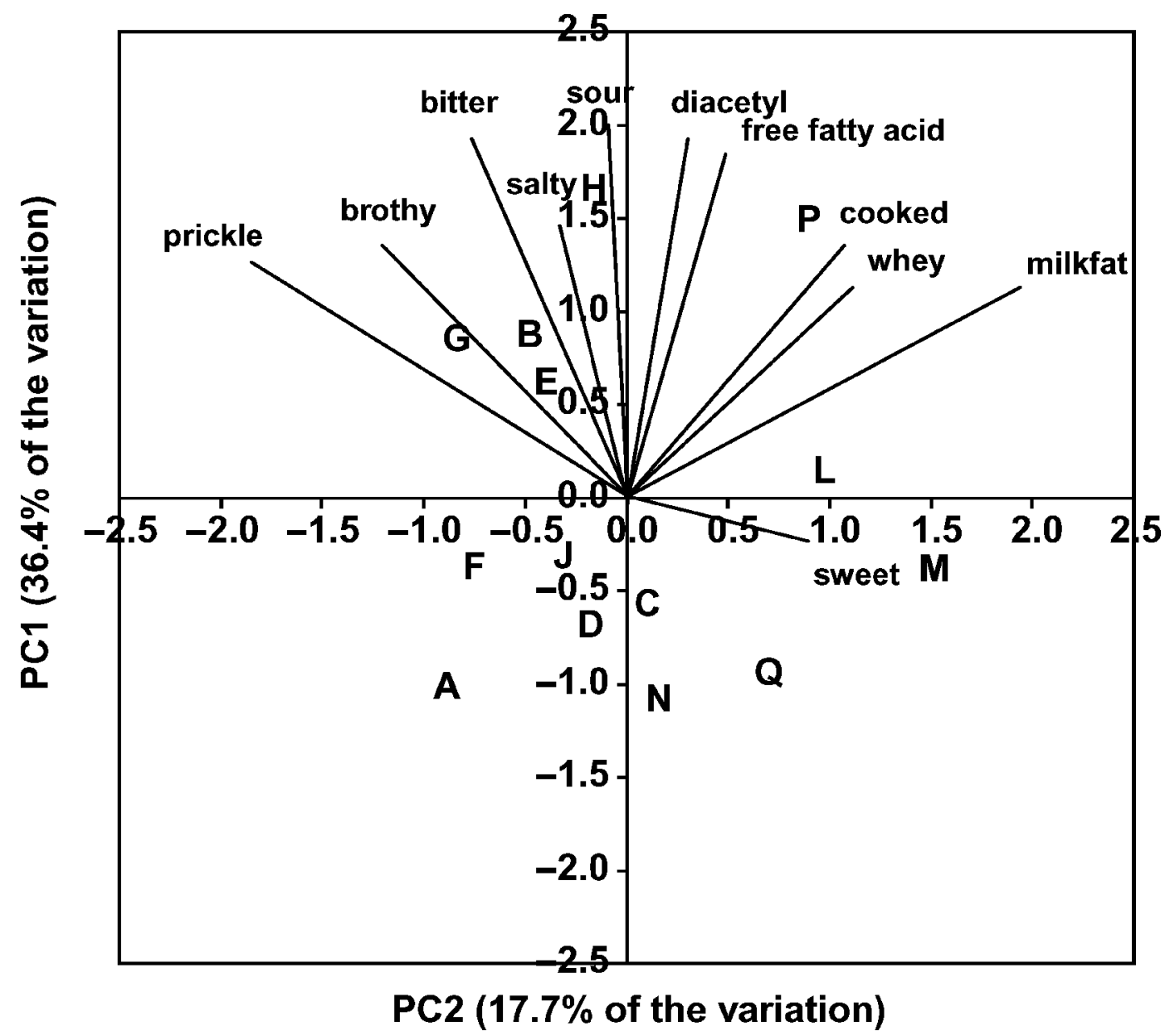

Figure 1. Flavor variability among the 14 different brands of Chihuahua cheese made with raw milk (brands A-H, J) or pasteurized milk (brands L-N, P, Q); vectors represent flavor descriptors. PC1, first principal component; PC2, second principal component.

Flavor scores for each brand of Chihuahua cheese varied very little throughout the year $(P<0.05)$ and indicated a stable flavor profile, although there were a few exceptions that varied with the brand. Variations found in 1 or 2 of the brands were sufficient for significant $(P$ $<0.05$ ) seasonal $\times$ brand interactions for salty, sour, and cooked flavors. Cheeses made in the spring had the highest bitter and cooked scores, RM-2 had its highest salty score, and PM-1 had its highest sour score. Prickle mouthfeel and FFA flavor were detected in both RM cheeses but not consistently. Overall flavor profiles (averaged for the year) for the RM and PM cheeses were similar to the profile generated from the 14 brands collected in late spring, with the RM cheeses having significantly higher bitter and sour flavors than the PM cheeses.

Overall, the textural attributes of Chihuahua cheeses placed throughout the middle range of scoring (Table 5). The hand firmness, hand springiness, and first-bite firmness ranged from 9.1 to 9.5 ; chewdown degree of breakdown was at 7.3; hand rate of recovery, first-bite fracturability, chewdown cohesiveness, chewdown adhesiveness, and residual smoothness of mouth coating ranged from 6.2 to 6.5 ; and chewdown smoothness was at 5.8. When scored according to the reference cheeses described by Brown et al. (2003), Chihuahua cheeses were firm but not hard (hand and first bite) and had some springiness. They recovered fairly well from hand compression and did not fracture or chew down easily. They were slightly sticky in the mouth when chewed, and the chewed mass was somewhat smooth (before and after expectorating). Sensory texture scores for Chihuahua cheese fit into what would be expected for a semihard cheese containing around 40\% moisture.

The texture scores for Chihuahua cheese showed variation among the different brands of cheeses in different seasons (Table 5). Season, brand, and season $\times$ brand interactions were significant $(P<0.05)$ for almost all 
Table 5. Texture scores for the 2 brands of Chihuahua cheese made with raw milk (RM) and the 2 brands made with pasteurized milk (PM) manufactured during the Mexican winter (w), spring (sp), or late summer $(\mathrm{ls})^{1}$

\begin{tabular}{|c|c|c|c|c|c|c|c|c|c|c|}
\hline Cheese season & HFm & HSp & HRc & FFm & FFr & $\mathrm{CBr}$ & CCo & CAd & $\mathrm{CSm}$ & $\mathrm{RSm}$ \\
\hline \multicolumn{11}{|l|}{$\mathrm{RM}$} \\
\hline \multicolumn{11}{|l|}{ RM-1 } \\
\hline $\mathrm{w}$ & $8.1^{\mathrm{d}}$ & $10.3^{\mathrm{ab}}$ & $7.5^{\mathrm{abc}}$ & $7.1^{\mathrm{ef}}$ & $5.7^{\mathrm{cd}}$ & $7.4^{\mathrm{ab}}$ & $7.1^{\mathrm{b}}$ & $6.3^{\mathrm{abc}}$ & $6.3^{\mathrm{cd}}$ & $6.6^{\mathrm{bcd}}$ \\
\hline $\mathrm{sp}$ & $10.1^{\mathrm{ab}}$ & $10.9^{\mathrm{a}}$ & $6.2^{\mathrm{c}}$ & $9.5^{\mathrm{abcd}}$ & $6.1^{\text {bcd }}$ & $6.7^{\mathrm{b}}$ & $5.9^{\text {bcde }}$ & $5.8^{\mathrm{bc}}$ & $5.3^{\text {cde }}$ & $5.8^{\text {cde }}$ \\
\hline ls & $11.6^{\mathrm{a}}$ & $2.0^{\mathrm{c}}$ & $1.0^{\mathrm{d}}$ & $10.7^{\mathrm{a}}$ & $8.2^{\mathrm{a}}$ & $6.8^{\mathrm{b}}$ & $4.8^{\text {cde }}$ & $6.7^{\mathrm{abc}}$ & $3.4^{\mathrm{f}}$ & $3.4^{\mathrm{f}}$ \\
\hline Average & $9.9^{\mathrm{a}}$ & $7.8^{\mathrm{c}}$ & $5.0^{\mathrm{d}}$ & $9.0^{\mathrm{a}}$ & $6.6^{\mathrm{a}}$ & $7.0^{\mathrm{b}}$ & $5.9^{\mathrm{b}}$ & $6.2^{\mathrm{b}}$ & $5.0^{\mathrm{c}}$ & $5.3^{\mathrm{c}}$ \\
\hline \multicolumn{11}{|l|}{ RM-2 } \\
\hline $\mathrm{w}$ & $8.3^{\text {cd }}$ & $10.5^{\mathrm{ab}}$ & $8.0^{\mathrm{abc}}$ & $7.8^{\mathrm{de}}$ & $6.2^{\mathrm{bcd}}$ & $6.9^{\mathrm{b}}$ & $6.4^{\mathrm{bcd}}$ & $5.8^{\mathrm{bc}}$ & $6.3^{\mathrm{cd}}$ & $6.8^{\mathrm{bcd}}$ \\
\hline sp & $10.7^{\mathrm{ab}}$ & $11.7^{\mathrm{a}}$ & $7.3^{\mathrm{bc}}$ & $9.9^{\mathrm{abc}}$ & $6.4^{\text {abcd }}$ & $5.9^{\mathrm{b}}$ & $4.6^{\mathrm{de}}$ & $5.2^{\mathrm{c}}$ & $4.4^{\text {ef }}$ & $4.5^{\mathrm{ef}}$ \\
\hline ls & $10.3^{\mathrm{ab}}$ & $2.7^{\mathrm{c}}$ & $1.3^{\mathrm{d}}$ & $10.1^{\mathrm{ab}}$ & $7.9^{\mathrm{ab}}$ & $7.3^{\mathrm{ab}}$ & $5.8^{\text {bcde }}$ & $5.7^{\mathrm{c}}$ & $4.6^{\text {def }}$ & $5.6^{\text {cde }}$ \\
\hline Average & $9.7^{\mathrm{a}}$ & $8.4^{\mathrm{c}}$ & $5.6^{\mathrm{c}}$ & $9.2^{\mathrm{a}}$ & $6.8^{\mathrm{a}}$ & $6.7^{\mathrm{b}}$ & $5.6^{\mathrm{b}}$ & $5.6^{\mathrm{b}}$ & $5.2^{\mathrm{c}}$ & $5.7^{\mathrm{bc}}$ \\
\hline RM mean & $9.8^{\mathrm{A}}$ & $8.1^{\mathrm{B}}$ & $5.3^{\mathrm{B}}$ & $9.1^{\mathrm{A}}$ & $6.7^{\mathrm{A}}$ & $7.7^{\mathrm{A}}$ & $5.8^{\mathrm{B}}$ & $5.9^{\mathrm{B}}$ & $5.1^{\mathrm{B}}$ & $5.5^{\mathrm{B}}$ \\
\hline \multicolumn{11}{|l|}{ PM } \\
\hline \multicolumn{11}{|l|}{ PM-1 } \\
\hline $\mathrm{w}$ & $6.2^{\mathrm{e}}$ & $8.3^{\mathrm{b}}$ & $6.4^{\mathrm{bc}}$ & $5.9^{\mathrm{f}}$ & $3.5^{\mathrm{e}}$ & $9.3^{\mathrm{a}}$ & $9.2^{\mathrm{a}}$ & $7.8^{\mathrm{ab}}$ & $9.3^{\mathrm{a}}$ & $9.1^{\mathrm{a}}$ \\
\hline $\mathrm{sp}$ & $9.8^{\mathrm{bc}}$ & $11.3^{\mathrm{a}}$ & $6.5^{\mathrm{bc}}$ & $8.4^{\text {bcde }}$ & $4.9^{\mathrm{de}}$ & $9.5^{\mathrm{a}}$ & $9.1^{\mathrm{a}}$ & $7.9^{\mathrm{a}}$ & $8.2^{\mathrm{ab}}$ & $8.2^{\mathrm{ab}}$ \\
\hline ls & $9.8^{\mathrm{bc}}$ & $10.7^{\mathrm{a}}$ & $8.1^{\mathrm{ab}}$ & $10.5^{\mathrm{a}}$ & $6.3^{\mathrm{bcd}}$ & $7.5^{\mathrm{ab}}$ & $6.6^{\mathrm{bc}}$ & $6.1^{\mathrm{abc}}$ & $5.0^{\text {cdef }}$ & $6.1^{\text {cde }}$ \\
\hline Average & $8.5^{\mathrm{b}}$ & $10.0^{\mathrm{b}}$ & $7.0^{\mathrm{b}}$ & $8.2^{\mathrm{b}}$ & $4.9^{\mathrm{b}}$ & $8.8^{\mathrm{a}}$ & $8.3^{\mathrm{a}}$ & $7.3^{\mathrm{a}}$ & $7.6^{\mathrm{a}}$ & $7.9^{\mathrm{a}}$ \\
\hline \multicolumn{11}{|l|}{ PM-2 } \\
\hline $\mathrm{w}$ & $8.1^{\mathrm{d}}$ & $11.9^{\mathrm{a}}$ & $9.2^{\mathrm{a}}$ & $8.2^{\text {cde }}$ & $5.9^{\mathrm{cd}}$ & $6.5^{\mathrm{b}}$ & $6.3^{\text {bcde }}$ & $6.2^{\mathrm{abc}}$ & $6.6^{\mathrm{bc}}$ & $7.0^{\mathrm{bc}}$ \\
\hline $\mathrm{sp}$ & $11.4^{\mathrm{a}}$ & $10.4^{\mathrm{ab}}$ & $7.5^{\mathrm{abc}}$ & $10.7^{\mathrm{a}}$ & $6.9^{\mathrm{abc}}$ & $5.9^{\mathrm{b}}$ & $4.4^{\mathrm{e}}$ & $5.8^{\mathrm{bc}}$ & $0.4^{\mathrm{ef}}$ & $4.8^{\mathrm{def}}$ \\
\hline ls & $9.3^{\text {bcd }}$ & $11.4^{\mathrm{a}}$ & $7.7^{\mathrm{abc}}$ & $10.1^{\mathrm{ab}}$ & $6.8^{\mathrm{abc}}$ & $7.6^{\mathrm{ab}}$ & $7.6^{\mathrm{ab}}$ & $6.7^{\mathrm{abc}}$ & $6.1^{\mathrm{cd}}$ & $7.3^{\mathrm{abc}}$ \\
\hline Average & $9.6^{\mathrm{a}}$ & $11.3^{\mathrm{a}}$ & $8.2^{\mathrm{a}}$ & $9.6^{\mathrm{a}}$ & $6.5^{\mathrm{a}}$ & $6.7^{\mathrm{b}}$ & $6.1^{\mathrm{b}}$ & $6.2^{\mathrm{b}}$ & $5.7^{\mathrm{b}}$ & $6.4^{\mathrm{b}}$ \\
\hline PM mean & $9.0^{\mathrm{B}}$ & $10.6^{\mathrm{A}}$ & $7.6^{\mathrm{B}}$ & $8.9^{\mathrm{A}}$ & $5.7^{\mathrm{B}}$ & $6.8^{\mathrm{B}}$ & $7.2^{\mathrm{A}}$ & $6.7^{\mathrm{A}}$ & $6.6^{\mathrm{A}}$ & $7.1^{\mathrm{A}}$ \\
\hline
\end{tabular}

\footnotetext{
${ }^{\mathrm{a}-\mathrm{f}}$ Means for individual brands within a column that do not share the same lowercase letter are different $(P<0.05)$.

$\mathrm{A}, \mathrm{B}$ Overall means for RM or PM cheeses within a column that do not share the same uppercase letter are different $(P<0.05)$.

${ }^{1}$ See Table 2 for detailed explanation of descriptors: HFm, hand firmness; HSp, hand springiness; HRc, hand rate of recovery; FFm, first-bite firmness; FFr, first-bite fracturability; CBr, chewdown degree of breakdown; CCo, chewdown cohesiveness; CAd, chewdown adhesiveness; CSm, chewdown smoothness; and RSm, residual smoothness of mouth coating. RM mean, mean of RM-1 average and RM-2 average; PM mean, mean of PM-1 average and PM-2 average.
}

texture attributes; the only exceptions were seasonal effects for chewdown degree of breakdown and chewdown adhesiveness. The most dramatic seasonal difference was the significant $(P<0.05)$ reduction of the hand springiness and hand rate of recovery values for the late summer RM cheeses, which indicated that the cheeses lost their elastic nature and could not recover their original shape after hand compression. Compared with cheeses made in the spring or late summer, winter cheeses were significantly $(P<0.05)$ softer (hand or first bite). The RM-1 and PM-1 late summer cheeses had significantly $(P<0.05)$ higher first-bite fracturability and lower chewdown smoothness and residual smoothness of mouth coating scores than at other times of the year, indicating that the cheese fractured easily and did not form a smooth mass when chewed. The breakdown and adhesiveness properties of the cheeses did not change significantly $(P<0.05)$ over the year.

When examined by brand (averaged over the year, Table 5), PM-1 cheeses had significantly $(P<0.05)$ higher chewdown and residual smoothness properties and lower firmness and fracture attributes than the other 3 brands. For the first-bite and most of the chewdown attributes, the PM-2 cheeses were not significantly $(P<$ 0.05) different from the RM cheeses. Overall, the PM cheeses had significantly higher scores for hand springiness, hand rate of recovery, chewdown cohesiveness, chewdown adhesiveness, chewdown smoothness, and residual smoothness of mouth coating than the RM cheeses.

Principal component analysis illustrated the general variability in texture among the different brands of RM and PM Chihuahua cheeses during the 3 Mexican seasons (Figure 2). The first PC accounted for $66.4 \%$ of the variation, whereas the first 3 components accounted for $95.1 \%$ of the variation. Three of the 4 winter cheeses were clustered in the upper-right quadrant (positive PC1 and PC2 values) along the hand rate of recovery and hand springiness vectors. Three of the 4 spring cheeses were clustered in the lower-right quadrant (negative $\mathrm{PC} 1$ and positive PC2 values). The 2 late summer RM cheeses were clustered in the lower-left quadrant (negative PC1 and PC2 values) and were closest to the firstbite property vectors. Two of the PM cheeses (same 


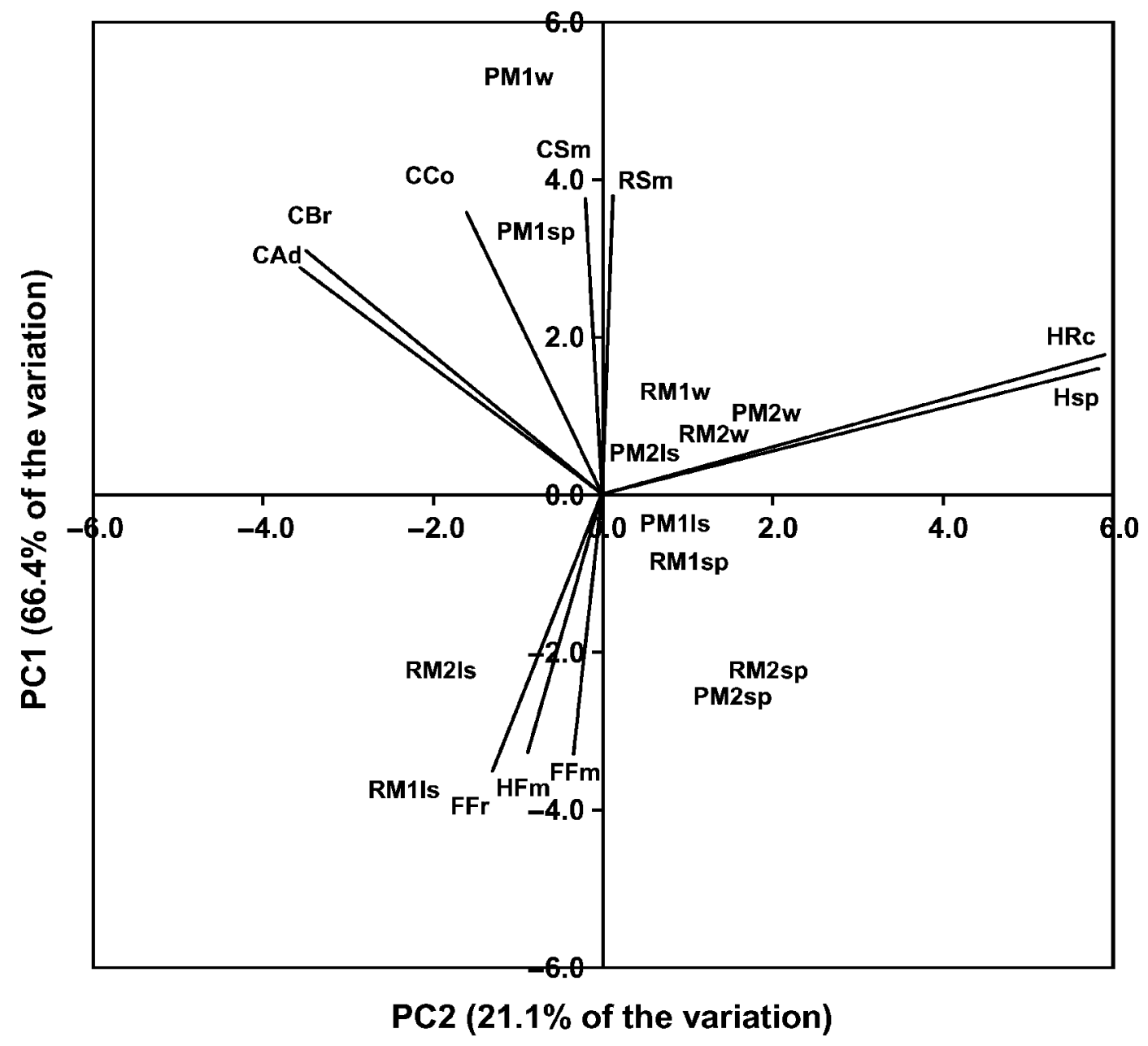

Figure 2. Texture variability of the 4 brands of Chihuahua cheese made with raw milk (RM-1 and RM-2) or pasteurized milk (PM-1 and PM-2) and tested at 3 different times of the year (late summer, ls; winter, w; and spring, sp). Vectors represent the following texture descriptors: HFm, hand firmness; HSp, hand springiness; HRc, hand rate of recovery; FFm, first-bite firmness; FFr, first-bite fracturability; $\mathrm{CBr}$, chewdown degree of breakdown; CCo, chewdown cohesiveness; CAd, chewdown adhesiveness; CSm, chewdown smoothness; and RSm, residual smoothness of mouth coating. PC1, first principal component; PC2, second principal component.

brand) were clustered in the upper-left quadrant (positive PC1 and negative PC2 values) near the chewdown cohesiveness and chewdown smoothness property vectors. The PC analysis illustrated the diversity in texture of the Chihuahua cheeses found among the different brands and throughout the year.

The current sensorial texture protocol was developed specifically to identify and separate cheeses based on hand, first-bite, and chewing evaluations (Drake et al., 1999a), and correlates very well with the separation of cheeses by instrumental rheology (Drake et al., 1999b; Brown et al., 2003). This study supports the ability of the sensory approach to determine slight but significant differences between cheeses and shows that brand variation changes slightly throughout the Mexican seasons. Rheology studies of Chihuahua cheese support the slight variability in texture among the brands of fresh cheese (Van Hekken et al., accepted) and the textural differences that occur because of the change in seasons for the manufacture of the cheeses (our unpublished data, 2006).

Variations of flavor and texture among the different brands of Chihuahua cheese were expected to some degree because of the diversity in cheese-making protocols used by the manufacturers. Cheese-making steps were based on Cheddar cheese manufacture with slight procedural modifications occurring among the different production sites. A thorough discussion of the processing steps is presented by Tunick et al. (accepted). The impact of seasonal variation on the flavor and texture of the cheeses may be due in part to the changes in milk composition of the pasture-fed animals, as well as to the mi- 
croflora present in the RM and PM cheeses, especially considering the diversity and concentration of microflora found in the phase 1 cheeses (Bricker et al., 2005).

Consumers rely very heavily on their senses to evaluate the quality of cheese. Although instrumental evaluation of the chemical and physical properties of cheese can provide considerable information about the cheese, current approaches still cannot match the complex sensitivity of the human senses. Descriptive analysis provides critical information about the sensory properties of cheese and plays an integral part in defining the quality traits of cheeses.

\section{CONCLUSIONS}

Establishing the flavor and texture profiles for the traditionally made Chihuahua cheese manufactured in Chihuahua, México, provides a critical link in defining and characterizing the quality traits of this unique ethnic cheese. The Chihuahua cheeses are mildly flavored semihard cheeses. Raw milk cheeses are more bitter and sour and are perceived as being softer than the pasteurized milk cheeses. Slight seasonal changes in the flavors and textures of Chihuahua cheese were detected by the trained panelists. Because consumer acceptance of a cheese is based on its flavor and texture, understanding the sensory identity of the cheese will provide critical guidance as new ways are explored to improve yield, shelf life, and uniformity of the cheese.

\section{ACKNOWLEDGMENTS}

The authors thank John Phillips for statistical guidance, James Shieh for determining the cheese composition, Maryanne Wildermuth for assistance in conducting flavor panels, and all the panelists involved in this study. Partial support for this project was funded by the USDA, Foreign Agricultural Service, Scientific Cooperative Research Program, and Dairy Management Inc. (Rosemont, IL).

\section{REFERENCES}

AOAC. 1997. Official Methods of Analysis. 16th ed. Association of Official Analytical Chemists International, Gaithersburg, MD.

Avsar, Y. K., Y. Karagul-Yuceer, M. A. Drake, T. K. Singh, Y. Yoon, and K. R. Cadwallader. 2004. Characterization of nutty flavor in Cheddar cheese. J. Dairy Sci. 87:1999-2010.
Bricker, A. L., D. L. Van Hekken, V. M. Guerrero, and A. A. Gardea. 2005. Microflora isolated from Mexican Mennonite-style cheeses. Food Prot. Trends 25:637-640.

Brown, J. A., E. A. Foegeding, C. R. Daubert, M. A. Drake, and M. Gumpertz. 2003. Relationships among rheological and sensorial properties of young cheeses. J. Dairy Sci. 86:3054-3067.

Dirección General de Normas. 1994. Quesos Madurados. Norma Oficial Mexicana. 121-SSA1-1994. Secretaría de Salud, México City, México.

Drake, M. A. 2004. Defining dairy flavor. J. Dairy Sci. 87:777-784.

Drake, M. A., and G. V. Civille. 2003. Flavor lexicons. Compr. Rev. Food Sci. Food Safety 2:33-40.

Drake, M. A., P. D. Gerard, and G. V. Civille. 1999a. Ability of hand evaluation versus mouth evaluation to differentiate texture of cheese. J. Sens. Stud. 14:425-441.

Drake, M. A., P. D. Gerard, J. P. Kleinhenz, and W. J. Harper. 2003. Application of an electronic nose to correlate with descriptive sensory analysis of aged Cheddar cheese. Lebensm. Wiss. Technol. 36:13-20.

Drake, M. A., P. D. Gerard, V. D. Truong, and C. R. Daubert. 1999b. Relationship between instrumental and sensory measurements of cheese texture. J. Texture Stud. 30:451-476.

Drake, M. A., W. Herrett, T. D. Boylston, and B. G. Swanson. 1996 Lecithin improves texture of reduced fat cheeses. J. Food Sci. 61:639-642.

Drake, M. A., S. C. McIngvale, P. D. Gerard, K. R. Cadwallader, and G. V. Civille. 2001. Development of a descriptive language for Cheddar cheese. J. Food Sci. 66:1422-1427.

Drake, M. A., V. D. Truong, and C. R. Daubert. 1999c. Rheological and sensory properties of reduced-fat processed cheeses containing lecithin. J. Food Sci. 64:744-747.

Kosikowski, F. V., and V. V. Mistry. 1997a. Page 266 in Cheese and Fermented Milk Foods. Vol. 1. 3rd ed. F. V. Kosikowski, LLC, Westport, CT.

Kosikowski, F. V., and V. V. Mistry. 1997b. Page 212 in Cheese and Fermented Milk Foods. Vol. 2. 3rd ed. F. V. Kosikowski, LLC, Westport, CT.

Meilgaard, M., G. V. Civille, and B. T. Carr. 1999. Descriptive analysis techniques. Pages 161-170 in Sensory Evaluation Techniques, 3rd ed. CRC Press, Boca Raton, FL.

National Agricultural Statistics Service. 2005. Dairy Products: 2004 Summary. USDA - National Agricultural Statistics Service, Washington, DC. http://usda.mannlib.cornell.edu/reports/nassr/dairy/ pdp-bban/daryan05.pdf

SAS Institute Inc. 2001. SAS for Windows. Release 8.02. SAS Institute Inc., Cary, NC.

Shakeel-Ur-Rehman, N. Y. Farkye, T. Considine, A. Schaffner, and M. A. Drake. 2003. Effects of standardization of whole milk with dry milk protein concentrate on the yield and ripening of reducedfat Cheddar cheese. J. Dairy Sci. 86:1608-1615.

Suriyaphan, O., M. A. Drake, X. Q. Chen, and D. R. Cadwallader. 2001. Characteristic aroma components of British farmhouse Cheddar cheese. J. Agric. Food Chem. 49:1382-1387.

Tungjaroenchai, W., M. A. Drake, and C. H. White. 2001. Influence of adjunct cultures on ripening of reduced fat Edam cheeses. J. Dairy Sci. 84:2117-2124.

Tunick, M. H., D. L. Van Hekken, F. J. Molina-Corral, P. M. Tomasula, J. Call, J. Luchansky, and A. A. Gardea. Mexican Chihuahua cheese: Make procedures, composition, protein profiles, and microbiology. Int. J. Dairy Technol. (accepted)

Van Hekken, D. L., and N. Y. Farkye. 2003. Hispanic cheeses: The quest for queso. Food Technol. 57:32-38.

Van Hekken, D. L., M. H. Tunick, P. M. Tomasula, F. J. Molina-Corral, and A. A. Gardea. Mexican Chihuahua cheese: Rheology of fresh cheese. Int. J. Dairy Technol. (accepted) 